\title{
Underlay tympanoplasty with tunneling and placement of graft in anterior canal wall
}

S. N. Ganguly ${ }^{1}$, N.S Reddy ${ }^{2}$, A. Shrestha ${ }^{3}$, S. Acharya ${ }^{4}$, B. Bhattarai ${ }^{5}$

${ }^{1}$ Professor, ${ }^{2}$ Professor \& HOD, ${ }^{3}$ Lecturer, ${ }^{4}$ Resident, ${ }^{5}$ Audiologist, Department of ENT, CMS-TH, Bharatpur, Nepal

\begin{abstract}
Tympanoplasty is one of the commonest surgical procedures done by ENT Surgeons. Though it has a long history of about six decades, various techniques have been advocated. Today most widely used technique is underlay. Overlay technique is reserved for total perforation. A modification of the underlay technique with anterior tunneling and placement of graft in anterior canal wall was tried and evaluated. Cases were selected from patients attending CMS-TH, Bharatpur. Seventy (70) cases were included and results were evaluated.
\end{abstract}

Keywords: Tympanoplasty, underlay technique, overlay technique, graft, anterior tunneling.

\section{Introduction}

Tympanoplasty is one of the commonest surgical procedures done by ENT Surgeons. Though it has a long history of about six decades, various techniques have been advocated by different authors for a successful outcome. ${ }^{1}$

Today most widely used technique is underlay, where graft is placed medial to drum remnant and handle of malleus. The overlay technique is reserved for total perforation. The underlay technique is relatively simple and ideal for posterior perforation and has a high success rate, but middle ear space is diminished and has a chance of medialisation of graft. And in cases of large anterior perforation, graft placement is not as satisfactory as it should be by this technique and there is always a fear in the mind of surgeon regarding collapse of

Correspondence: S.N. Ganguly

E-mail: soumen_ganguli@yahoo.co.in graft and subsequent residual perforation in anterior-superior region. To avoid graft collapse, adequate gelfoam packing in this region has been advocated, which holds the graft against the under surface of drum remnant while epethelisation is taking place. ${ }^{1}$ Still residual perforations do occur in this segment, frustrating both patient and surgeon. A modification of the technique with anterior tunneling and placement of graft in anterior canal wall has been advocated by many authors. ${ }^{2,3}$ The present paper demonstrates the technical details of the procedure and discusses the result of 70 cases in last two years (2007-2009).

\section{Materials and methods}

Case was selected from patients attending CMSTH. Cases of revision surgery and cases where the perforation has not involved anterior-superior 
S. N. Ganguly et al, Underlay tympanoplasty with tunneling and placement.

quadrant and cases which needed mastoidectomy were excluded from the study. All the cases had under gone thorough clinical and audiological evaluation. Radiological evaluation was not done routinely. Examination under microscope was done in all cases and remnant of anterior margin of perforation and whether it is clearly seen or not is noted.

\section{Surgical technique}

Anesthesia: The procedure is done usually under local anesthesia with adrenaline infiltration. Only in children GA is used.

\section{Approach}

Depending whether the anterior margin is clearly seen or not under microscope, approach is decided. When anterior margin is not seen clearly, post aural approach is undertaken. After exposure, margin is freshened and tympanomeatal flap is elevated in usual manner (12'-6' O'clock in RE).

\section{Making the tunnel}

An incision of about $2 \mathrm{~mm}$ is made in anterior canal wall from 1-2 O'clock (RE) few mm above the annulus. Flap is elevated and tympanic membrane with annulus is dislodged from the notch.

\section{Placement of graft}

Temporal fascia graft already prepared is placed under the handle of malleus, tympanomeatal flap and a tongue shaped portion is withdrawn through the tunnel. No gel foam was given in middle ear. Gel foam and packing is given in external canal.

\section{Postoperative care}

Pack is removed after 7 days. Gel foam is not disturbed. No drop is given. Antibiotics and other medicines are continued for 3 weeks. Gel foams are removed after 3 weeks putting ear drops.

\section{Results}

70 cases were included in the study. The average age is 29 years with male female ratio 2:1 (Age range is from 12-58 years). Graft was taken in 68 cases. Only in two cases graft was rejected as a whole but no residual perforation was noted in any case. Preoperatively hearing losses were 30-40 dB in most of the cases. (Table -1 )

\begin{tabular}{cc}
\hline HL & No. of Cases \\
\hline $20-30 \mathrm{~dB}$ & 11 \\
$30-40 \mathrm{~dB}$ & 49 \\
$40-50 \mathrm{~dB}$ & 10 \\
\hline
\end{tabular}

Post-operatively, assessment of hearing was done after 3 months. There was definitive improvement of hearing in all cases with closure of narrowing of air bone gap where graft has taken up.(Table - 2)

\begin{tabular}{cc}
\hline HL $(\mathrm{ABG})$ & No $(\%)$ \\
\hline $0-10 \mathrm{~dB}$ & $54(77 \%)$ \\
$11-30 \mathrm{~dB}$ & $10(14 \%)$ \\
$21-30 \mathrm{~dB}$ & $4(6 \%)$ \\
$>30 \mathrm{~dB}$ & $2(3 \%)$ \\
\hline
\end{tabular}

No cases of lateralization, anterior blunting, epithelial pearl formation was noted. In few cases granulations developed over the surface of 
neotympanic membrane and anterior canal wall but these responded well with chemical cautery and antibiotic steroid ear drops.

\section{Discussion}

Tympanoplasty was first developed by Banzer in 1640. Over the year and with advent of microscope various techniques have been evolved to improve tympanopalsty results. These include overlay, underlay, swing door, 3 flaps, over under lay etc. ${ }^{4,5}$ The most commonly used technique today is underlay technique for its simplicity and high success rate without any risk of graft cholesteatoma and anterior blunting. But the disadvantage is that it is less suitable for large anterior perforation where the drum remnant is minimum. There is a risk of graft collapse, middle ear volume reduction and adhesion of graft to promontory.

To avoid these some surgeons advocated overunderlay technique where graft is placed over handle of malleus. But these techniques require manipulation of handle of malleus which may traumatize inner ear with chance of sensorineural hearing loss. ${ }^{5}$

Besides, the firm attachment of membrane to the umbo causes laceration of residual tympanic membrane and epithelial cells may be left unnoticed on the malleus. Again graft may detach from the handle of malleus during the healing process with consequent reduction in sound conduction efficiency. ${ }^{5}$

Modification of under lay technique by placing the graft in anterior canal wall obviates the drawbacks of this technique and voids the disadvantages of other techniques. By this technique the graft is so secured in anterior canal wall that there is no chance of fall back and collapse of the graft and even no gel foam packing is required to support the graft. In few cases some technical difficulty raised to separate the flap from anterior canal wall specially by end aural approach and in such cases much carefulness is needed so that flap does not tear.

Another important point is that tympanic annulus should never be elevated beyond 2-O'clock (in RE), because an intact anterior tympano-meatal angle is essential for optimal functional result. Violation of this attachment of annulus induces blunting of the tympanomeatal angle and lateralisation of drum and reduces vibrating property of the drum. ${ }^{3}$

The graft taken up rate was noticed in this study and is $97 \%$ and no residual perforation is noted. This is comparable to other studies. ${ }^{6}$

Though improvement of hearing depends on several factors not only on graft taken up, significant improvement was noted in $90 \%$ cases. In conclusion, underlay tympanoplasty with placement of graft in anterior canal wall by tunneling is very good technique for treating perforations in anterior quadrant especially with minimum drum remnant. The graft take over rate is excellent and hearing improvement is also good without any residual perforation and complications.

\section{References}

1. J M Kartush, E.M. Michaelides, Z. Becvarovski et al. Over-Underlay tympanoplasty. Laryngoscope 2002: 112 (5); 802-7. 
S. N. Ganguly et al, Underlay tympanoplasty with tunneling and placement.

2. H. Ludman, T Wright. Diseases of the Ear, $6^{\text {th }}$ ed. New York, Oxford University Press. 1998:430-2

3. U. Fish, J. May, T. Linder, et al. Tympanoplasty, Mastoidectomy, and Stapes surgery. $2^{\text {nd }}$ ed.New york, Thieme.2007:33.

4. B.K. Roychaudhari. 3 flap Tymplanoplasty-A Simple and sure success technique, IJOHNS 2004: 56(3); 196200.
5. F. Fiorino, F Barbieri. 'Over-underlay' myringoplasty with umbo-anchor graft. J Laryngol Otol 2008: 122(8); 854-7.

6. A.K. Shah, D.M. Munshi, S.N. Ghosh, et al. Evaluation of improvement of hearing in type-I tympanoplasty and its influencing factors. IJLO. 58(3); 253-8.

7. M.E. Glasscock, G.E. Shambaugh. Surgery of the ear, $4^{\text {th }}$ ed. Philadelphia, WB Saunders.1990: 339-43. 